\title{
Know it when you see it? The qualities of the communities people describe as "diverse" (or not)
}

\author{
Maria Abascal \\ New York University
}

\author{
Flavien Ganter \\ Columbia University
}

\begin{abstract}
We explore what people mean by "diversity" when they use the term to describe real communities. "Diversity" can refer to multiple differencesethnoracial, economic, etc. It may also refer to multiple dimensions of the same difference, i.e., heterogeneity or group representation. Analyzing a survey of Chicago area residents, we ask: (1) When people describe a community as diverse, on which kinds of differences are they drawing? (2) Within each relevant difference, are evaluations of diversity predicted by heterogeneity, the share of specific groups, or both? Findings suggest respondents associate diversity primarily with a community's ethnoracial attributes and secondarily with its economic attributes. Within ethnoracial attributes, both heterogeneity and the share of disadvantaged ethnoracial groups, especially Blacks, predict assessed diversity. Within economic attributes, income inequality predicts assessed diversity, albeit negatively; the representation of poor people does not. Qualitative responses reveal varied understandings of diversity while confirming the dominance of ethnoracial attributes.
\end{abstract}

Pre-Print.-Accepted for publication in City E Community. June 5, 2022.

The authors are listed alphabetically; both contributed equally to this work. Thanks to Katharine Khanna for research assistance. For valuable feedback, we are grateful to Lev Asimow, Paul DiMaggio, Tom DiPrete, Denia Garcia, the participants of the Race, Ethnicity, and Migration Workshop at Columbia University, the Race/Ethnicity Workshop at New York University, and the Russell Sage Foundation Seminar Series. The research was supported by the National Science Foundation (CAREER \#1845177). Direct correspondance to Maria Abascal, Department of Sociology, New York University, 295 Lafayette Street, New York, NY 10012. Email: m.abascal@nyu.edu. 


\section{INTRODUCTION}

The term "diversity" is increasingly used in interpersonal and institutional discourse (Berrey 2015; Edelman et al. 2001; Lentin and Titley 2008; Vertovec 2012). Diversity is understood as a value that expresses a normative commitment and as a descriptor that characterizes groups and communities (Bell and Hartmann 2007). As a descriptor, diversity can refer to different, sometimes contradictory, qualities. First, diversity can refer to multiple types of difference. In neighborhoods, for example, diversity can be associated with differences in terms of race/ethnicity and economic status, as well as age, sexuality, and political views (Berrey 2005, 2015; Hoekstra and Gerteis 2019). Second, even when diversity is pinned to one type of difference, like race/ethnicity, it can refer to heterogeneity or to the representation of disadvantaged groups (Abascal et al. 2021a,b). Heterogeneity concerns the distribution of people across groups in a community, whereas representation concerns the share of community members in disadvantaged groups. These conceptions are not only analytically distinct, they are occasionally at odds. For example, in an area with only White and Black residents, ethnoracial heterogeneity is highest when the two groups are in equal proportion, whereas representation is higher as the disadvantaged group is larger (e.g., 90 percent Black residents).

This study interrogates the link between subjective evaluations of diversity and objective community traits. We catalog the properties of the residential communities that people choose to describe as "diverse." We ask: (1) When people describe their communities as diverse, on which kinds of differences-ethnoracial, economic, etc.-are they explicitly and implicitly drawing? (2) Within each relevant difference, are evaluations of diversity predicted by heterogeneity, the representation of certain groups, or both? Because diversity, especially when it is understood in ethnoracial terms, may mean different things based on one's own background, we explore how evaluations vary by respondent race/ethnicity.

We analyze a survey of 2,401 Chicago metro area residents who were asked if they would say their town or neighborhood "is a diverse place." This unique dataset allows us to explore what people mean by diversity, not when they discuss diversity in the abstract, but when they apply the term to real-world communities. We focus on evaluations of residential communities, as opposed to educational, professional, or other communities. Residential communities are the subject of a controversial line of work on the negative consequences of ethnoracial diversity (e.g., Dinesen et al. 2020), work which has been criticized for conflating heterogeneity and representation conceptions of diversity (Abascal et al. 2021a). 
The Chicago metro area is a strategic research site for several reasons, chiefly that neighborhood boundaries are widely recognized and agreed upon by Chicago residents and institutions (Sampson 2012:78). This allows us to explore how the decision to describe a neighborhood as diverse is associated with the attributes of that neighborhood, as understood by the people who live there.

To anticipate the main findings, people explicitly associate diversity with ethnoracial differences followed by economic differences. In addition, the objective ethnoracial attributes of a community better predict whether residents describe it as "diverse" than its economic attributes. Within ethnoracial attributes, both heterogeneity and the share of disadvantaged ethnoracial groups, especially Blacks, predict assessed diversity. Although patterns of association with group shares vary depending on respondents' ethnoracial background, the relationship between assessed diversity and ethnoracial heterogeneity is strong and consistent across respondents. Within economic attributes, the representation of poor people does not predict assessed diversity, but income inequality does-at least for White respondents-albeit negatively. We discuss potential explanations for this finding and rule out mechanisms related to ethnoracial inequality, segregation, and gentrification. The finding suggests Whites may view inequality as being at odds with a normatively desirable trait like diversity.

Our findings challenge the notion-implicit as much in corporate mission statements and college websites as in Supreme Court decisions-that "diversity" describes an apparent, agreed-upon quality (Bauman et al. 2014). Instead, assessments of diversity draw on multiple, sometimes contradictory criteria, like ethnoracial heterogeneity and percent Black. We conclude by considering the implications of diversity ambiguity. In particular, we discuss how lay associations between diversity and heterogeneity, when combined with research that makes claims about the negative consequences of diversity, can fuel calls for curbing integration and immigration.

\section{BACKGROUND \& LITERATURE}

Diversity discourse has been on the rise for several decades in the United States (Berrey 2015; Edelman et al. 2001; Vertovec 2012) and Europe (Lentin and Titley 2008). Today, the term "diversity" is used to describe neighborhoods, schools, and corporations. In the words of Vertovec, we are "living in the age of diversity" (2012:287).

A growing area of work explores how people understand and describe diver- 
sity. In an important example of this work, Bell and Hartmann (2007) asked respondents across four US metro areas, "What does diversity mean to you?" The authors distinguished programmatic understandings of diversity from descriptive ones.

Programmatic understandings treat diversity as a "moral imperative" (Bell and Hartmann 2007:899), a "presumptively positive buzzword" used to "symbolically amplify aspects of social life as of a higher and more venerable order" (Berrey 2015:42). Diversity's moralistic inflection comes through in a wealthy white respondent's assertion that diversity is something "you believe in" (Hoekstra and Gerteis 2019:206), college websites' descriptions of diversity as a "core value" (Berrey 2015:58; also Okuwobi et al. 2021), and a middle-class parent's characterization of their "ideal" neighborhood as "a little bit of everybody" (Darrah-Okike et al. 2020:381; also Underhill 2019). Moralistic understandings also underlie "diversity happy talk": uplifting accounts of diversity as something that makes life "fun," "interesting," and "exciting" (Bell and Hartmann 2007:899).

Happy talk notwithstanding, not everyone agrees that diversity is desirable. Ehnographic research in multiracial neighborhoods has uncovered substantial ambivalence toward diversity among residents (Burke 2012; Mayorga-Gallo 2014). ${ }^{1}$ And in their efforts to expose their families to people from diverse racial backgrounds, all but the most committed middle-class Whites stop short of living in multiracial neighborhoods (Underhill 2019). More broadly, and fueled by research on diversity and social capital, the mainstream press and far-right online forums routinely feature claims that diversity has negative consequences (see discussion in Abascal et al. 2021a).

\section{A DESCRIPTOR OF WHAT?}

Moralistic understandings of diversity coexist with an understanding of "diversity" as an uncomplicated, objective descriptor. As Bauman et al. explain, "people often talk about diversity as if everyone ought to "know it when they see it"” (2014:1354).

If diversity describes things, what kinds of things does it describe? "Diversity" can refer to multiple attributes or differences. In educational and corpo-

${ }^{1}$ Relatedly, when people are asked to describe the composition of the neighborhoods where they would feel most and least comfortable living, they describe ethnoracially heterogeneous neighborhoods in both cases (Krysan et al. 2016). 
rate contexts, research has documented a staggering array of associations. For example, in the diversity statements of their college applications, White applicants appeal to numerous individual-level differences-e.g., being home-schooled, playing sports, being good at math (Kirkland and Hansen 2011). In corporate contexts, managers associate diversity with broad, occasionally indecipherable qualities (e.g., "It's about allowing employees to bring their dogs to work"), in addition to race/ethnicity and gender (Embrick 2011).

In neighborhoods, "diversity" can also take on multiple descriptive associations, for example, with race/ethnicity, socioeconomic status, age, sexuality, and politics (Berrey 2005, 2015; Hoekstra and Gerteis 2019). Rajasekar et al. (2021), for example, find that people describe their locales as more "socially and culturally" diverse if they live in counties that are heterogeneous in terms of race/ethnicity, religion, partisanship, or poverty status. However, research in neighborhoods also suggests "diversity" retains a strong association with race/ethnicity. For example, when prompted to describe experiences with neighborhood diversity, people most often describe interactions with ethnoracial outgroups (Bell and Hartmann 2007; also see Rajasekar et al. 2021). In addition to race/ethnicity, research suggests a robust association between neighborhood diversity and economic differences (Bell and Hartmann 2007; Berrey 2005, 2015; Burke 2012; Hoekstra and Gerteis 2019; Rajasekar et al. 2021).

Critiques of diversity discourse hinge on the fact that "diversity" can be used to characterize multiple types of difference as "analogous" (Berrey 2015:26; Lentin and Titley 2008). This fact has led some scholars to label diversity a tool of colorblind racism (Bonilla-Silva [2003] 2018; Burke 2012; Doane 2017; Moore and Bell 2011). ${ }^{2}$ Lentin and Titley explain:

"Diversity discourses recognise an array of differences in society, but in knitting them together into a tableau of plurality and richness they rob difference of its critical and contextual significance: equalising all differences." (2008:13)

More broadly, ambiguity around the differences connoted by diversity allows organizations to "move the goalpost," that is, to reformulate the criteria for being diverse to conform to existing compositions, without altering those composi-

${ }^{2}$ Though, as Mayorga-Gallo contends, "Unlike color-blind racism, however, diversity ideology does not insist that race is unimportant . . . but frames race as one marker of difference" among others (2019:1792). 
tions through admission or hiring. At the same time, ambiguity may be part of the term's strategic appeal, allowing "diversity" to salvage unpopular race-based policies and practices by cultivating support among women, sexual minorities, and others (Berrey 2015). In the corporate sector, for example, human resource departments preserved controversial anti-discrimination practices by rebranding them "diversity management" (Kelly and Dobbin 1998). And in higher education, affirmative action survived an important legal challenge when the US Supreme Court enshrined "diversity" as a compelling state interest (Hirschman et al. 2016; Moore and Bell 2011) in Bakke v. California (1978), a stance it reaffirmed in Grutter v. Bollinger (2003).

\section{HETEROGENEITY \& REPRESENTATION}

Even when diversity is pinned to one attribute, say race/ethnicity, diversity may refer to two dimensions of that attribute: heterogeneity or representation. Analytically, "diversity" is synonymous with heterogeneity, a property that depends only on the number of groups in a community and their relative sizes: "The larger the number of groups and the more evenly the population is divided among them, the greater is the heterogeneity" (Blau 1977:31). This conception of diversity informs the widespread use of heterogeneity indexes in studies of ethnoracial diversity; these indexes do not distinguish, say, a community that is $80 \%$ White and $20 \%$ Black from a community that is $80 \%$ Black and $20 \%$ White. Indeed, as a concept and measure, heterogeneity treats groups "interchangeably, like pieces on a checkers board” (Abascal and Baldassarri 2015:730).

However, conceptions of diversity may also prioritize the representation of specific groups. In this conception, the community that is $80 \%$ Black is more diverse than the community that is $80 \%$ White. Research confirms that people evaluating ethnoracial diversity take into account not just the number and size of the groups, but also their identities. For example, both White and Black Americans judge a group with four White and two Black members to be more diverse than a group with four White and two Asian members (Bauman et al. 2014; also Unzueta et al. 2012). Importantly, Americans from different ethnoracial backgrounds disagree on the specific groups that make a community diverse, with Blacks, Latinos, and Asians prioritizing the representation of ingroup members (Abascal et al. 2021b). ${ }^{3}$

\footnotetext{
${ }^{3}$ In a similar vein, Krysan et al. (2016) find that both White and Black Chicagoans prefer neigh-
} 
Heterogeneity and representation are not only analytically distinct; they are occasionally at odds. Consider a predominately Black neighborhood. This neighborhood is not diverse if diversity is evaluated based on ethnoracial heterogeneity; it is diverse if diversity is evaluated based on non-White representation.

Diversity's association with both heterogeneity and representation has important implications for research and policy. A large social science literature links "diversity" to lower trust, lower public goods provision, and other undesirable consequences (for reviews, van der Meer and Tolsma 2014; Dinesen et al. 2020). In the most famous example of this work, Putnam (2007) concludes that more "diverse" communities are plagued by lower trust and solidarity, both within and across ethnoracial groups. However, studies in this area either operationalize diversity as immigrant or non-White share (see Abascal et al. 2021a) or, like Putnam (2007), they use heterogeneity indexes that are collinear with immigrant and non-White shares in Western countries (Kustov and Pardelli 2018). As a result, their findings are consistent with a different, more plausible conclusion: not that heterogeneity depresses social capital for everyone, but that social capital is depressed in disadvantaged, minority communities. Instead, many studies advance premature claims about the undesirable consequences of heterogeneity, claims that have fueled opposition to affirmative action and immigration (Thernstrom et al. 2012; Richwine 2009) along with calls for curbing mixture in educational and residential contexts (see Abascal et al. 2021b). The elision between heterogeneity and immigrant and non-White shares that suffuses this literature not only implies that people associate "diversity" with both heterogeneity and representation, it also reveals the consequences of doing so, an issue to which we return in the conclusion. Most broadly, diversity's association with potentially contradictory criteria-heterogeneity and representation-may undermine diversity initiatives by making it difficult to gauge whether diversity has been achieved.

\section{QUESTION \& APPROACH}

Our goal is to shed light on lay meanings of the term "diversity" by cataloguing the qualities of the communities that people describe as diverse. In prior, qualitative research on the meanings of diversity, respondents are typically asked to define diversity in general terms. Bell and Hartmann, for example, asked respondents

borhoods where their in-group is largest, and that Latinos prefer one where Whites and Latinos are equally represented. 
"What does [diversity] mean to you?" (2007:904; see also Collins 2011; Embrick 2011; Hoekstra and Gerteis 2019). Rather than asking people to define diversity in the abstract, we ask people whether they would describe their communities as diverse (or not). Like Rajasekar et al. (2021), our goal is to link subjective evaluations of diversity to objective community traits. We build on their work using (1) a more fine-grained proxy of community (neighborhoods vs. counties), (2) measures of both heterogeneity and representation, and (3) an outcome measure that allows respondents to interpret diversity broadly, without priming "social and cultural" differences. More generally, our approach resembles that of Krysan (1998), who leveraged numeric compositions to unpack the meanings of another vague but idealized concept: "integration."

Like Berrey (2005), Bell and Hartmann (2007), Hoekstra and Gerteis (2019), Rajasekar et al. (2021), and others we focus on diversity in residential contexts. Two considerations guide our focus. First, recent decades have witnessed a rise in "global neighborhoods" where multiple ethnoracial groups stably co-reside (Logan and Zhang 2010; Zhang and Logan 2016). Second, residential communities are the subject of a large line of work on the negative consequences of ethnoracial diversity that has been criticized precisely for conflating different dimensions of diversity (Abascal et al. 2021a).

Specifically, we explore how Chicago area residents characterize the neighborhoods and (in the case of suburbanites) towns where they live. ${ }^{4}$ Towns and neighborhoods are socially meaningful units that shape the people and environments that residents can readily access. Importantly, the boundaries of Chicago neighborhoods are widely recognized by residents and local institutions (Sampson 2012). The Chicago City Council, for example, approved a map of Chicago neighborhoods based on a survey of residents (City of Chicago 2006). Agreement over geographic boundaries is critical for our analyses, allowing us to link people's evaluations of their places of residence, as they understand and experience them, with the objective qualities of those same places. In addition, Chicago neighborhoods and towns vary widely in terms of their ethnoracial, economic, and other traits. Substantial variation is needed to disentangle (1) associations across neighborhood attributes (e.g., ethnoracial versus economic), as well as (2) associations across dimensions of the same attribute (e.g., ethnoracial heterogeneity versus eth-

${ }^{4}$ The Chicago metropolitan area, or Chicagoland, is home to just over 8.5 millions inhabitants. It spans Cook, DeKalb, DuPage, Grundy, Kane, Kendall, Lake, McHenry, and Will counties, and contains the city of Chicago. 
noracial minority representation). We expand on this issue in the next section.

On the one hand, we might expect Chicago area residents would be more likely than residents of other metropolitan areas to describe their communities as diverse. Chicago is exceptionally multiethnic (Logan and Zhang 2010). For much of the twentieth century, the city's ethnoracial landscape was dominated by Black and White Americans, including those of German, Irish, Italian, and Polish descent (Holli and Jones 1995). They were joined by sizable numbers of Hispanics, who recently surpassed Blacks as the largest ethnoracial minority in Chicago (Armentrout 2017). On the other hand, considerable segregation may dampen residents' perceptions of diversity. Chicago consistently ranks among the most segregated cities in the United States (Logan and Stults 2011).

In what follows, we address several questions. First, when people describe their town or neighborhood as "diverse," to which of its traits are they explicitly and implicitly referring? Regarding explicit associations with diversity, we examine which types of differences respondents are most likely to mention when explaining their decision to describe their community as "diverse" (RQ1a). In line with previous research, we confirm that respondents are most likely to mention ethnoracial differences. Economic differences, the next most frequently mentioned, are mentioned by many fewer respondents.

Next, we explore implicit associations with diversity. Specifically, we ask whether the decision to describe a community as diverse is in fact predicted by that community's ethnoracial traits or its economic ones (RQ1b). If both types of differences play a role, does one play a bigger role than the other? Two facts lead us to expect that a community's ethnoracial properties will better explain assessed diversity than will its economic properties: first is the historical link between diversity discourse and race-targeted policies; second is people's tendency to mention cross-racial interactions when asked to describe diversity (Bell and Hartmann 2007).

Finally, we look within communities' ethnoracial traits and economic traits, separately, to disentangle the predictive role of heterogeneity and representation. First, are assessments of diversity associated with ethnoracial heterogeneity, with the representation of disadvantaged ethnoracial groups, or with both (RQ2a)? Second, are assessments of diversity associated with economic heterogeneity-i.e., inequality-with the representation of economically disadvantaged groups (i.e., poor people), or with both (RQ2b)?

We attend to differences across respondents from different ethnoracial back- 
grounds. Experiments reveal that people from different ethnoracial backgrounds associate different ethnoracial groups with diversity (Unzueta and Binning 2010). And in interview research, White, Black, and Latino parents contrasted diverse neighborhoods with different kinds of homogeneous neighborhoods (DarrahOkike et al. 2020). For example, homogeneously White neighborhoods were an especially salient reference for White parents. People from different ethnoracial backgrounds may also be more or less likely to associate diversity with heterogeneity versus representation (Abascal et al. 2021a). ${ }^{5}$ Cross-group differences can hinder consensus on interventions and policies related to diversity, especially when disagreement cuts across groups with different stakes in such policies (Abascal et al. 2021a).

\section{DATA \& METHODS}

We analyze the 2018 Chicago Metropolitan Area Neighborhood Study (CMANS). The survey was designed by Thomas K. Ogorzalek, Traci Burch, Matthew Nelsen, Numar Ramanathan, and Reuel Rogers. It was fielded online by Nielsen Research with a sample of 2,401 Chicagoland resident adults. The sample was drawn from an online panel, with quotas for race, gender, and income. In addition, CMANS oversampled (1) residents of gentrifying ZIP code areas within Chicago, (2) residents of suburban ZIP code areas identified as becoming less White, and (3) Black residents. Using the 2016 IPUMS census release, we constructed sampling weights to correct for oversampling and deviations from the sociodemographic composition of Chicagoland. These weights are based on the joint distribution of age, educational attainment, and household income, as well as five ethnoracial categories. We trimmed weights so that the largest weight is no more than 100 times larger than the smallest one.

CMANS respondents were asked to give the name of their street and the cross street at the nearest intersection. We successfully geolocated $86.3 \%$ of respondents. We then matched respondents to the neighborhoods (for city residents) or towns (for suburbanites) where they live and linked them to the characteristics of those communities, based on five-year estimates from the American Community Survey (ACS; 2014-2018). Neighborhood boundaries are available from the city government based on a survey conducted by the Department of Planning.

${ }^{5}$ More broadly, people from different ethnoracial backgrounds disagree on the preferred composition of their ideal neighborhood (Krysan et al. 2016). 
Because the ACS does not provide data at the town or neighborhood levels, we aggregate census tract estimates to obtain neighborhood characteristics, and ZIP code tabulation area (ZCTA) estimates to obtain town characteristics. ${ }^{6}$ We chose to present findings based towns and neighborhoods, rather than tracts, because we are more confident that they are meaningful units for respondents, and because they better match the wording of the survey questions. Notably, the main conclusions of our paper hold if we instead use census tracts (see Figures A2 and A3 in the supplemental information).

\section{Variables}

Our dependent variables are based on responses to the following items:

When you think about your [neighborhood/town], would you say that it is a diverse place?

What do you mean when you say that your [neighborhood/town] is [diverse/not diverse]?

"Neighborhood" was displayed to respondents within the city of Chicago, and "town" to respondents in the suburbs. For the second item, "diverse" was displayed to respondents who answered "Yes" in response to the previous question; "not diverse" was displayed to respondents who answered "No."

Given diversity's moral inflection, respondents may feel compelled to describe their communities as diverse. ${ }^{7}$ In this respect, however, our measure is no different from other survey items about race, for which social desirability biases have long been documented (e.g., Krysan 1998). Additionally, normative pressures notwithstanding, nearly one-fifth of CMANS respondents do not describe their community as diverse. As we discuss in the Results section, this variation is critical for examining the predictors of assessed diversity.

Our primary independent variables are ethnoracial and economic attributes of respondents' town or neighborhood. Arguably, the perceived ethnoracial and

\footnotetext{
${ }^{6}$ Towns do not exist as a census geographic unit. The closest available unit are places, but they only cover part of Chicagoland-namely the most densely portion of each town. To construct a unit that makes up a full partition of Chicagoland, we aggregate ZCTAs into towns. In most cases, each ZCTA is associated with a unique town; exceptions typically consist in very small towns appended to a portion of a bigger town in the ZCTA, in which cases we consider that the small town is part of the bigger one.

${ }^{7}$ Although it is worth remembering that research in multiracial neighborhoods has found that residents openly express substantial ambivalence toward diversity (Burke 2012; Mayorga-Gallo 2014).
} 
economic makeup of communities should matter more than their objective makeup. Research has documented Americans' distorted perceptions of the racial makeup of their environments at various geographical levels (Alba et al. 2005; Wong 2007). On the other hand, perceptions at the local level are less distorted than those at the national level and, importantly, the correlation between perceived and objective characteristics is strong (Wong 2007).

We examine two ethnoracial attributes. The first is ethnoracial heterogeneity, captured by the complement of a normalized Herfindahl-Hirschamn Index (HHI):

$$
\text { Heterogeneity } \equiv 1-\frac{\sum_{r}\left(s^{(r)}\right)^{2}-1 / 5}{1-1 / 5}
$$

where $s^{(r)}$ is the share of respondents identified in ethnoracial group $r$, of five groups: non-Hispanic Whites, non-Hispanic Blacks, Hispanics, non-Hispanic Asians, and all others. The HHI can be interpreted as the probability that two people who are randomly selected from a community belong to the same group. Possibly, people infer diversity based on more fine-grained groups, e.g., Mexicans, Puerto Ricans, Dominicans, etc. Possibly, they infer diversity based on coarser groups, e.g., Whites versus non-Whites. ${ }^{8}$ The second ethnoracial attribute-representationcorresponds to the community shares of White, Black, Hispanic, and Asian residents. ${ }^{9}$ We examine two economic attributes: household income inequalityrepresented by the Gini index-and the share of households below the poverty threshold. ${ }^{10}$

Our models adjust for individual- and community-level differences. We adjust

${ }^{8}$ This critique has been raised of heterogeneity measures (Posner 2004), but it is true more generally of research that treats ethnoracial self-identification as a proxy for "groupness" (Abascal 2020).

${ }^{9}$ Several ethnoracial configurations can yield similar HHI (i.e., heterogeneity) values, which allows us to disentangle associations with heterogeneity from associations with representation. Of course, the association with heterogeneity may depend on the specific ethnoracial configuration of a neighborhood. For example, this association may differ between a neighborhood with three versus four equally-sized ethnoracial groups-even though HHI is similar for both. Our analyses implicitly average out configurational differences-first, because we do not have the empirical leverage to study them separately; second, and more importantly, because we seek to operationalize a general, analytical, conception of heterogeneity à la Blau (1977).

${ }^{10}$ Aggregating the Gini index from census tracts to neighborhoods/towns is not straightforward. The findings reported in this paper are based on an average Gini, which can be interpreted as the average level of exposure to economic inequality at the census tract level. However, using the maximum census tract Gini within neighborhoods/towns leads to similar findings. 
for respondent age (and squared age), gender, educational attainment, household income (logged and standardized by the square root of the household size), nativity, area of residence (city vs. suburbs), time in current neighborhood, and renting (vs. owning home). Supplementary models additionally adjust for selfreported political partisanship (Democrat vs. Republican vs. Independent), and for views on community diversity, captured by agreement with the statement "Having different kinds of people around makes a community work better" (positive vs. negative or neutral).

Finally, we stratify estimations by respondent race/ethnicity. Specifically, we distinguish self-identified non-Hispanic Whites (hereafter, Whites), non-Hispanic Blacks (hereafter, Blacks), Hispanics, and non-Hispanic Asians (hereafter Asians). Table 1 reports weighted descriptive statistics for individual-level variables.

Models also adjust for the following community-level differences: population size, population density, share of foreign-born residents, share of residents who own their homes, median household income, and share of residents who lived in the same house at least one year. Weighted descriptive statistics for these variables are reported in Table 2.

Either because respondents refused to respond to questions in the survey, or because they provided too little information to be precisely geolocated, the sample is not complete. To deal with non-response bias and preserve statistical power, we specified an imputation model and drew 20 imputed data sets from its posterior distribution by chained equations; we use these imputations in our analyses, although findings based on complete data only are virtually identical. Details of the imputed model are provided in the supplemental information C.

Model

We model the probability that a respondent describes their town or neighborhood as "a diverse place" $\left(a_{i}=1\right)$ as a function of their race/ethnicity, individual characteristics, and community characteristics, including town or neighborhood ethnoracial and economic attributes. We specify a multilevel model that accounts for the fact that respondents are nested within towns/neighborhoods, and that respondents who live in the same town/neighborhood might be affected by common, unobserved factors. Respondents are indexed by $i ; c_{i}$ and $r_{i}$ are respondent $i$ 's community of residence and self-identified race/ethnicity, respectively. $D_{c}$ is a vector of community ethnoracial and economic attributes, $Z_{c}$ is a vector of additional community attributes, and $X_{i}$ is a vector of individual attributes. We 
Table 1: Imputed sample weighted means, individual-level variables

\begin{tabular}{|c|c|c|c|c|c|}
\hline & \multirow{2}{*}{$\begin{array}{l}\text { Full } \\
\text { Sample }\end{array}$} & \multicolumn{4}{|c|}{ Respondents' Race/Ethnicity } \\
\hline & & White & Black & Hispanic & Asian \\
\hline \multicolumn{6}{|l|}{ Community assessed } \\
\hline Age $\ldots . . \ldots \ldots \ldots \ldots \ldots$ & $\begin{array}{c}47.8 \\
(16.3)\end{array}$ & $\begin{array}{c}49.8 \\
(16.3)\end{array}$ & $\begin{array}{c}47.6 \\
(16.2)\end{array}$ & $\begin{array}{c}41.6 \\
(14.9)\end{array}$ & $\begin{array}{c}44.6 \\
(15.6)\end{array}$ \\
\hline \multicolumn{6}{|l|}{ Sex: } \\
\hline Man ........ & .346 & .368 & .274 & .343 & .309 \\
\hline Woman .............. & .654 & .632 & .726 & .657 & .691 \\
\hline \multicolumn{6}{|l|}{ Education: } \\
\hline No Degree...... & .024 & .023 & .046 & .017 & .009 \\
\hline Some College ........... & .610 & .546 & .755 & .837 & .343 \\
\hline College Degree ........... & .214 & .250 & .111 & .103 & .368 \\
\hline Graduate Degree ......... & .152 & .181 & .088 & .043 & .280 \\
\hline $\begin{array}{l}\text { Household Income .......... } \\
\text { (thousands) }\end{array}$ & $\begin{array}{c}99.6 \\
(82.0)\end{array}$ & $\begin{array}{l}108.7 \\
(79.1)\end{array}$ & $\begin{array}{c}65.7 \\
(60.7)\end{array}$ & $\begin{array}{c}85.8 \\
(73.0)\end{array}$ & $\begin{array}{c}119.8 \\
(128.8)\end{array}$ \\
\hline Household size . ......... & $\begin{array}{c}2.6 \\
(1.3)\end{array}$ & $\begin{array}{c}2.5 \\
(1.2)\end{array}$ & $\begin{array}{c}2.7 \\
(1.5)\end{array}$ & $\begin{array}{c}2.8 \\
(1.4)\end{array}$ & $\begin{array}{c}2.9 \\
(1.3)\end{array}$ \\
\hline Foreign-Born ........... & .060 & .032 & .031 & .071 & .350 \\
\hline \multicolumn{6}{|l|}{ Area of Residence: } \\
\hline City of Chicago .......... & .304 & .271 & .307 & .378 & .419 \\
\hline Suburban Area ........... & .696 & .729 & .693 & .622 & .581 \\
\hline \multicolumn{6}{|c|}{ Time Since Establishment in the Neighborhood: } \\
\hline Less Than 5 Years ........ & .316 & .281 & .401 & .345 & .389 \\
\hline 5 To 19 Years........... & .367 & .349 & .401 & .372 & .446 \\
\hline$\leqslant 20$ Years / Entire Life... & .317 & .370 & .199 & .283 & .165 \\
\hline Renter................ & .251 & .191 & .444 & .317 & .249 \\
\hline \multicolumn{6}{|l|}{ Political affiliation: ${ }^{\mathrm{a}}$} \\
\hline Democrat........ & .577 & .492 & .785 & .735 & .545 \\
\hline Republican............ & .235 & .321 & .021 & .119 & .163 \\
\hline Independent........... & .189 & .187 & .193 & .146 & .292 \\
\hline $\begin{array}{l}\text { Positive views on community } \\
\text { diversity }^{\mathrm{a}} \ldots \ldots \ldots \ldots \ldots \ldots\end{array}$ & .276 & .288 & .249 & .261 & .256 \\
\hline$N$ units $\ldots \ldots \ldots \ldots \ldots \ldots$ & 593 & 388 & 226 & 91 & 140 \\
\hline$N$ respondents $\ldots \ldots \ldots \ldots \ldots$ & 2,376 & 1,597 & 464 & 124 & 191 \\
\hline
\end{tabular}

Notes.-All statistics are calculated over the 20 iterations of the imputation model. For continuous variables, means are reported together with standard deviations.

${ }^{\mathrm{a}}$ Variables only included in supplementary analyses. 


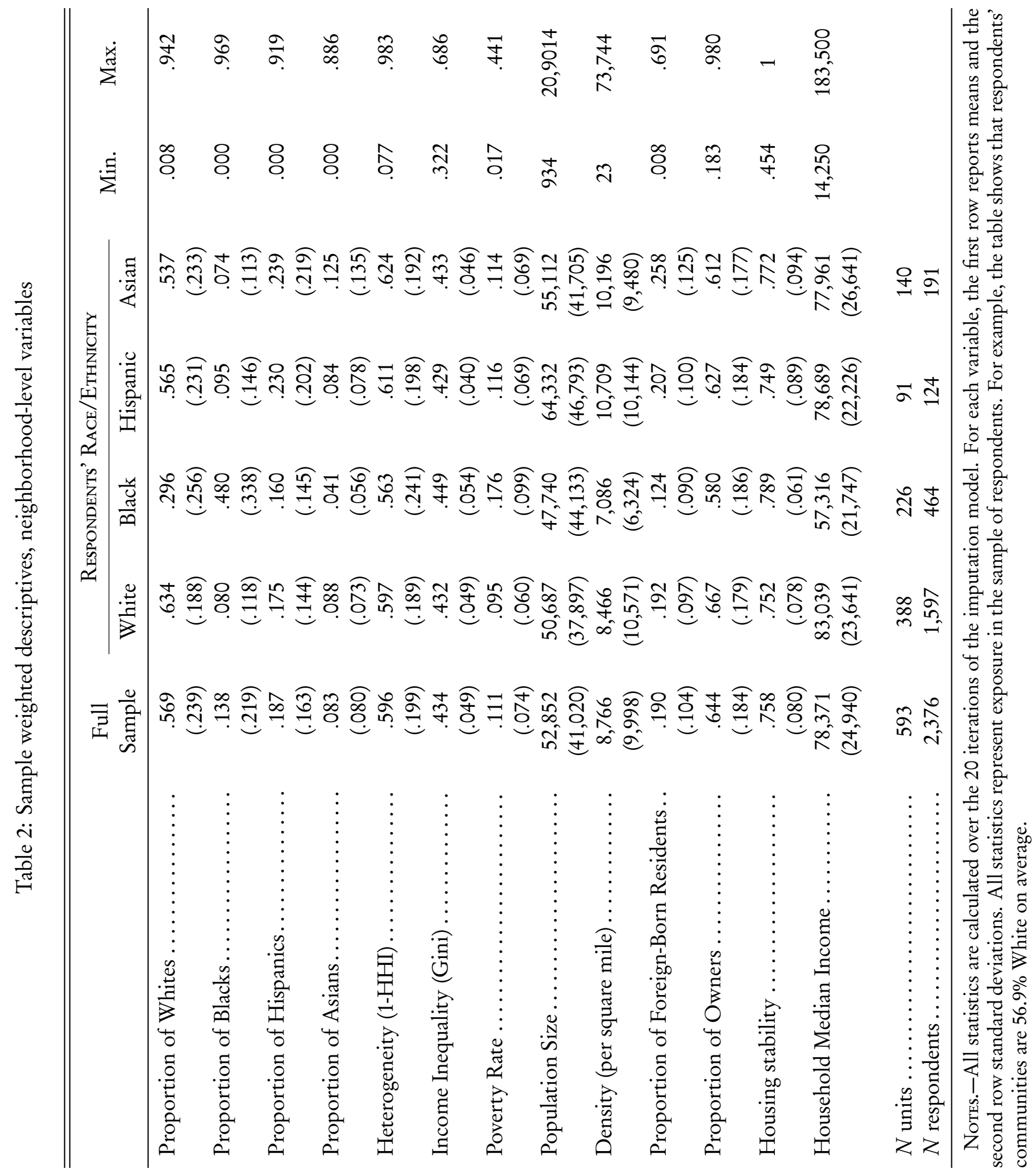


estimate the equation

$$
\mathbb{P}\left(a_{i}=1 \mid X_{i}, D_{c_{i}}, Z_{c_{i}}\right)=\operatorname{logit}^{-1}\left(\alpha_{c_{i} r_{i}}+X_{i}^{\prime} \beta\right) \quad \forall i
$$

in which we allow the intercept to vary across communities:

$$
\alpha_{c r} \mid D_{c}, Z_{c}=\alpha_{r}+D_{c}^{\prime} \delta_{r}+Z_{c}^{\prime} \gamma+\varepsilon_{c} \quad \forall c, r
$$

where $\varepsilon_{c} \sim \mathcal{N}\left(0, \sigma^{2}\right) .\left(\delta_{r}\right)_{r}$ is estimated separately for White, Black, Hispanic, and Asian respondents.

Scholars have raised concerns about controlling for both heterogeneity and minority share measures in the same models, because they are collinear when, for example, homogeneous communities are largely homogeneously White communities (Dinesen et al. 2020). Collinearity, however, is not an issue in empirical settings, like Chicagoland, where both homogeneously White communities and homogeneously non-White communities are observed. Although our heterogeneity and minority share measures are correlated, we observe enough variation to allow us to tease apart associations with heterogeneity versus minority share (see Figure A1 in the supplemental information).

Due to the limited sample size, the data are geographically sparse, and most towns and neighborhoods are only represented a few times in the sample. This geographic sparseness makes it difficult for conventional maximum likelihood estimations to converge. Instead, we leverage the versatility of Bayesian inference to estimate our model, sampling from the posterior distribution using the Hamiltonian Monte-Carlo (HMC) sampler provided by Stan (Stan Development Team 2018). ${ }^{11}$ We center and rescale all variables so that one unit corresponds to two standard deviations, and we set weakly informative priors on the estimated parameters: $\alpha_{r} \sim t_{4}\left(1.3,5^{2}\right) ; \delta_{r}, \beta, \gamma \sim t_{4}\left(0,5^{2}\right)$; and $\sigma \sim$ Cauchy $^{+}\left(0,5^{2}\right) .{ }^{12}$ "Weakly informative" priors regularize estimates for small samples, but are dominated by the likelihood for large samples (Gelman et al. 2008). Setting weakly informative priors allow us to put relatively more mass near the middle of the probability dis-

\footnotetext{
${ }^{11}$ In Bayesian inference, the posterior probability distribution is the probability distribution of an estimated parameter, given the data. If $p(Y \mid \theta)$ is the likelihood of the model (i.e., the probability of observing the data $\mathrm{Y}$ given the parameters $\theta$ ) and $p(\theta)$ is the prior distribution of $\theta$ (i.e., our prior knowledge of $\theta$ ), the posterior distribution $p(\theta \mid Y)$ is proportional to $p(Y \mid \theta) p(\theta)$. It can be interpreted intuitively, as the probability that a parameter falls within a range, given the data and what we knew about the parameter.

${ }^{12}$ The grand mean of the outcome variable is .782, which is approximately the inverse logit of 1.3 .
} 
tribution, and to regularize large, unstable coefficients, while allowing for large, stable coefficients. ${ }^{13}$

We fit the model for each of the 20 imputed data sets, then we individually check that the four chains have mixed well for 2,000 iterations per chain using Gelman-Rubin $\hat{R}$ (Gelman and Rubin 1992). We pool the posterior draws from the sampling iterations of all data sets. We report summary statistics for parameters' posterior distributions based on 160,000 draws. Our main quantity of interest is an "average marginal effect" (AME) that captures how much assessed diversity varies as each predictor increases by one unit, conditional on the other predictors included in the model. We calculate and report AMEs for each variable of interest, and for each of the four ethnoracial groups. Details regarding the specification of the reported AMEs are reported in the supplemental information B.

\section{Open-Response Coding}

After respondents reported whether they thought their town or neighborhood was diverse, they were asked to explain their answer by typing in a box. We coded the first 400 open responses to develop a set of codes that represented major themes. We shared these codes with another researcher who was not otherwise involved with the project. One author and this researcher coded all of the responses independently, then met to resolve disagreements. Disagreements were resolved through discussion. In many cases, resolution involved articulating a new rule for coding responses. In these cases, the rule was documented in a shared coding document and other responses whose coding might be affected were reviewed and decided on together.

\section{OPEN-RESPONSE FINDINGS}

When people describe their residential communities as diverse (or not), on which differences are they explicitly drawing? To answer this question, we turn to the open-response data, summarized in Table 3, which reports the weighted proportion of responses that received each code (column 1). A response could receive

\footnotetext{
${ }^{13}$ In logistic regressions, non-informative priors put most of the prior probability mass in the extreme tails of the probability distribution (near 0 and 1 ); this is not a desirable feature in our case. Moreover, when regressors are standardized, logit coefficients greater than five are rare because they correspond to huge shifts on the probability scale. For example, if the baseline probability is .5, an increase of two standard deviations in a variable associated with a coefficient of 2.5 corresponds to a shift to a probability of .993 .
} 
multiple codes. Columns 2 and 3 separate respondents who described their communities as diverse from those who described their communities as not diverse.

Types of Groups

Ethnoracial and national differences are the most frequently mentioned differences, mentioned by $88.6 \%$ of respondents. These responses mention the presence of ethnoracial or national/cultural groups, sometimes in general terms (e.g., "All races live here"), ${ }^{14}$ sometimes by mentioning specific groups (e.g., "Black, African, Vietnamese, Indian and Pakistani people"). ${ }^{15}$ Among respondents who alluded to specific groups, almost $80 \%$ referred to Whites, often to note their numerical hegemony. Only a few respondents mentioned Whites to report their low representation ("I am one of few whites in my neighborhood."). Blacks, Latinos, and Asians were mentioned by between $17 \%$ and $33 \%$ of respondents; they were even more likely to be mentioned by respondents who considered their towns or neighborhoods "diverse." 16

Socioeconomic differences are the next most frequently mentioned. They were mentioned by $14.4 \%$ of respondents, far less than the $88.6 \%$ who mentioned ethnoracial and national differences. Some responses refer to socioeconomic differences in general terms (e.g., "Different economic classes"); others mention specific groups (e.g., "most residents are middle income... many with a college degree"). Respondents drew on a range of characteristics to infer their neighbors' socioeconomic status, including occupation and housing type/prices. One respondent, for example, noted the presence of "lots of single family homes, so that

\footnotetext{
${ }^{14}$ Quotes edited for spelling and punctuation.

${ }^{15}$ We collapsed references to ethnoracial and national/cultural groups for several reasons. First, many respondents listed groups that are considered "racial" alongside those that are considered "national" or "cultural," suggesting a conceptual equivalence between them, as in the already cited quote when the respondent refers to Black people alongside African, Vietnamese, and Pakistani people. Second, some of the groups that respondents mentioned (e.g., "Hispanics," "Asians," "Indians") straddle the folk distinctions Americans draw between "race," "ethnicity," and "nation." Third, it is possible that some respondents, who were reluctant to use the terms "race," might have used the terms "nationalities" or "cultures" instead.

${ }^{16}$ Responses categorized "minorities represented" and "minorities underrepresented" could presumably be referring to homogeneity and thus be categorized as "no heterogeneity" as well. For example, the respondent who wrote "My area is very much white" could have been referring both to the underrepresentation of non-Whites and to the predominance of one group. To avoid overinterpreting the open-response data, we coded as "heterogeneity" or "no heterogeneity" only those responses that referred explicitly to the presence or absence of multiple groups ("many," "few," etc.) or to "mixture."
} 
Table 3: Weighted descriptive statistics of the open-response data (proportions)

\begin{tabular}{|c|c|c|c|c|}
\hline & $\begin{array}{c}\text { Full } \\
\text { sample }\end{array}$ & $\begin{array}{c}\text { "Diverse" } \\
\text { areas }\end{array}$ & $\begin{array}{c}\text { "Not } \\
\text { diverse" } \\
\text { areas }\end{array}$ & $t$-stat. \\
\hline & \multicolumn{4}{|c|}{ TyPe OF DifFERENCE } \\
\hline Ethnoracial or national .......... & .886 & .879 & .912 & $1.973^{*}$ \\
\hline Socioeconomic............... & .144 & .142 & .149 & .279 \\
\hline Religion..$\ldots \ldots \ldots \ldots \ldots \ldots$ & .085 & .083 & .093 & .576 \\
\hline Age $\ldots \ldots \ldots \ldots \ldots \ldots \ldots \ldots \ldots$ & .058 & .062 & .043 & 1.639 \\
\hline Gender or sexual identity ......... & .031 & .030 & .033 & .273 \\
\hline 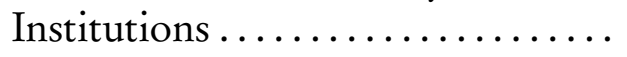 & .024 & .023 & .030 & .717 \\
\hline Politics ................... & .010 & .009 & .014 & .684 \\
\hline Other types................ & .020 & .019 & .026 & .702 \\
\hline Unspecified ................. & .068 & .074 & .046 & $1.841^{+}$ \\
\hline \multirow[t]{2}{*}{ Multiple types ............... } & .236 & .236 & .236 & .022 \\
\hline & \multicolumn{4}{|c|}{ SpeCIFIC RaCial Groups $^{\mathrm{a}}$} \\
\hline Whites . & .791 & .791 & .790 & .041 \\
\hline Blacks .... & .334 & .352 & .296 & 1.099 \\
\hline Latinos $\ldots \ldots \ldots \ldots \ldots \ldots \ldots$ & .274 & .329 & .154 & $3.164^{* *}$ \\
\hline \multirow[t]{2}{*}{ 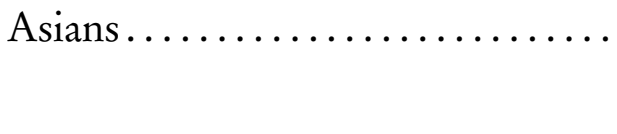 } & .169 & .209 & .083 & $3.594^{* * *}$ \\
\hline & \multicolumn{4}{|c|}{ Heterogeneity vs. REPRESENTATION } \\
\hline Heterogeneity ....... & .629 & .683 & .434 & $8.642^{* * *}$ \\
\hline No heterogeneity $\ldots \ldots \ldots \ldots \ldots$. & .029 & .022 & .054 & $2.750^{* *}$ \\
\hline Minorities represented .......... & .064 & .061 & .075 & .857 \\
\hline Minorities underrepresented ...... & .204 & .168 & .332 & $5.784^{* * *}$ \\
\hline$N \ldots \ldots \ldots \ldots \ldots \ldots \ldots \ldots \ldots$ & 2,220 & 1,647 & 573 & \\
\hline
\end{tabular}

${ }^{\text {a }}$ Proportions calculated among respondents who mention any of the four groups.

Noтеs.-Proportions in the first panel ("Types of difference") and the third panel ("Heterogeneity vs. representation") are calculated for the subsample of respondents who provided an open response. Categories are not exclusive, therefore columns do not sum to 1 . The unspecified category includes respondents who referred to differences between people without specifying differences of any concrete type. The fourth column reports the $t$-statistic of the proportion difference between respondents who live in "diverse" and "not diverse" communities (columns 2 and 3 ).

${ }^{+} p<.10 ;{ }^{*} p<.05 ;{ }^{* *} p<.01 ;{ }^{* * *} p<.001$ (two-tailed tests) 
prices some folks out."

Religion was brought up by $8.5 \%$ of respondents. Respondents referred to religion directly (e.g., "a wide variety of . . r religious backgrounds"), to religious denominations (e.g., "Christian," "Muslim"), to religious "faiths" or "beliefs," or to places of worship. $5.8 \%$ of respondents mentioned differences in terms of age (e.g., "There are young people. There are old people"). 3.1\% mentioned differences in terms of gender and sexual identity. These responses referred to the presence of neighbors who are gay, queer, or transgender. About one in five of these responses referred simply to neighbors who differ in terms of "gender," which is surprising, because neighborhoods are almost universally integrated by gender.

Finally, some respondents linked diversity to institutions (e.g., "festivals," "restaurants") or to politics (e.g., "political views," "Republicans," "Conservatives"). The "other types" category encompasses responses that refer to other types of groups, such as those based on family configurations or disability. About $7 \%$ of respondents referred to interpersonal differences too general to be classified, such as "Lots of people from different backgrounds" and "All types of people live here."

Again, the differences listed in Table 3 are not exclusive. In fact, almost one-quarter of respondents simultaneously alluded to several types of differences, sometimes up to four or five types. Not only may people associate various differences with diversity, many may also hold a multidimensional conception of diversity.

\section{Heterogeneity vs. Representation}

The last panel of Table 3 captures whether responses refer to heterogeneity, i.e., the distribution across groups and/or the representation of specific groups. Almost two-thirds of respondents provided a response consistent with a heterogeneity conception of diversity. These responses refer to the presence or absence of multiple groups, however "groups" are defined. One respondent, for example, wrote "One group of people living there only," leaving unspecified the type of group to which they were referring. Importantly, to receive a heterogeneity code, responses did not need to refer to the size of the groups present (and rarely did so). The understanding of diversity implied by many of these responses is that just one or a few people in each group (and sometimes just more than one group) is enough to qualify a community as diverse. For example, one such respondent wrote: "There are many different races that live in my town even though they 
make up a small percentage."

About one-quarter of respondents explicitly associated diversity with the representation of disadvantaged groups. These groups include non-Whites, immigrants, and poor people. Responses classified as "minorities represented" refer to substantial numbers of people in these groups. For example, one respondent wrote, "Lots of immigrants and people of color." Responses classified as "minorities underrepresented" refer to insubstantial numbers of people in these groups (e.g., "We have few black Americans") or to substantial numbers of people in advantaged groups (e.g., "My area is very much white").

Respondents who consider their communities "diverse" were about 1.6 times more likely to mention heterogeneity, whereas respondents who consider their communities "not diverse" were about 2.4 times more likely to mention the absence of heterogeneity. Similarly, respondents who consider their communities "not diverse" were twice as likely to mention the underrepresentation of minorities. In addition, those respondents who mentioned heterogeneity did so more often to flag the presence-rather than absence-of multiple groups, whereas those respondents who mentioned representation did so more often to flag the underrepresentation-rather the (over)representation-of minorities. This suggests that people may simultaneously hold both heterogeneity and representation conceptions and apply the criterion (or language) of heterogeneity to describe communities they consider diverse and of representation to describe communities they consider not diverse.

In sum, CMANS respondents were most likely to explicitly associate diversity with ethnoracial differences, followed by socioeconomic differences. This is in line with earlier, qualitative research, in which respondents consistently associate neighborhood diversity and ethnoracial and material differences between residents (Bell and Hartmann 2007; Berrey 2015; Burke 2012; Hoekstra and Gerteis 2019). This observation guides our attention to objective neighborhood ethnoracial and economic properties in our subsequent, quantitative analysis. ${ }^{17}$

\section{QUANTITATIVE FINDINGS}

A majority of respondents (78.2\%; Table 1) describe their neighborhood or town as diverse. That so many respondents describe their communities as diverse is re-

${ }^{17}$ It is possible that respondents were tempted to mention differences they thought would appeal to the social scientists carrying out the study. This limitation is shared by all studies on the meanings of diversity that use obtrusive data collection strategies. 
markable in one of the most segregated cities in the United States (Logan and Stults 2011); it might reflect the normative appeal of "diversity," to the larger Chicago area's multiethnic character, or both. Notably, a non-negligible share of respondents describe their neighborhoods as not diverse. In addition, respondents who describe their neighborhood or town as not diverse are spread out over virtually the entire area sampled by the survey (Figure 1). We leverage variation within Chicagoland to identify the ethnoracial and economic attributes that predict the decision to describe a community as diverse.

\section{Communities' Ethnoracial Attributes}

First, we estimate assessed diversity as a function of ethnoracial heterogeneity and ethnoracial group shares in respondents' towns and neighborhoods of residence, as well as individual- and community-level covariates. Figure 2 reports estimates for the associations between neighborhood ethnoracial heterogeneity, ethnoracial composition, and the probability of describing one's neighborhood as diverse. ${ }^{18}$ The figure reports both point estimates and Bayesian credible intervals; a 95\% percent credible interval indicates that the parameter of interest has a $95 \%$ chance of falling within the interval's bounds, given the data and model. We report high probability density intervals, that is, intervals that enclose the segment(s) of the posterior distribution with the highest density for a given level of credibility.

As expected, ethnoracial heterogeneity, captured by the HerfindhalHirschman index, is positively associated with assessed diversity for respondents of all ethnoracial backgrounds. A one-SD increase in ethnoracial heterogeneity $(+.199)$ is associated with an average increase in the probability of describing one's community as diverse of 11.5 percentage points for White respondents, 12.3 points for Black respondents, 7.1 points for Hispanic respondents, and 11.7 points for Asians respondents, adjusting for economic attributes. The association is statistically significant in all cases except for Hispanic respondents, for whom the coefficient is smaller and less precisely estimated.

Assessed diversity is also associated with the representation of ethnoracial minorities, although less clearly than with ethnoracial heterogeneity. Among White respondents, assessed diversity is significantly, positively associated with the share of Black residents and significantly, negatively associated with the share of Asian residents. A one-SD increase in the share of Black residents $(+.219)$ is associated

${ }^{18}$ We checked whether the associations with ethnoracial heterogeneity and ethnoracial group shares were non-linear; we did not detect statistically significant patterns. 


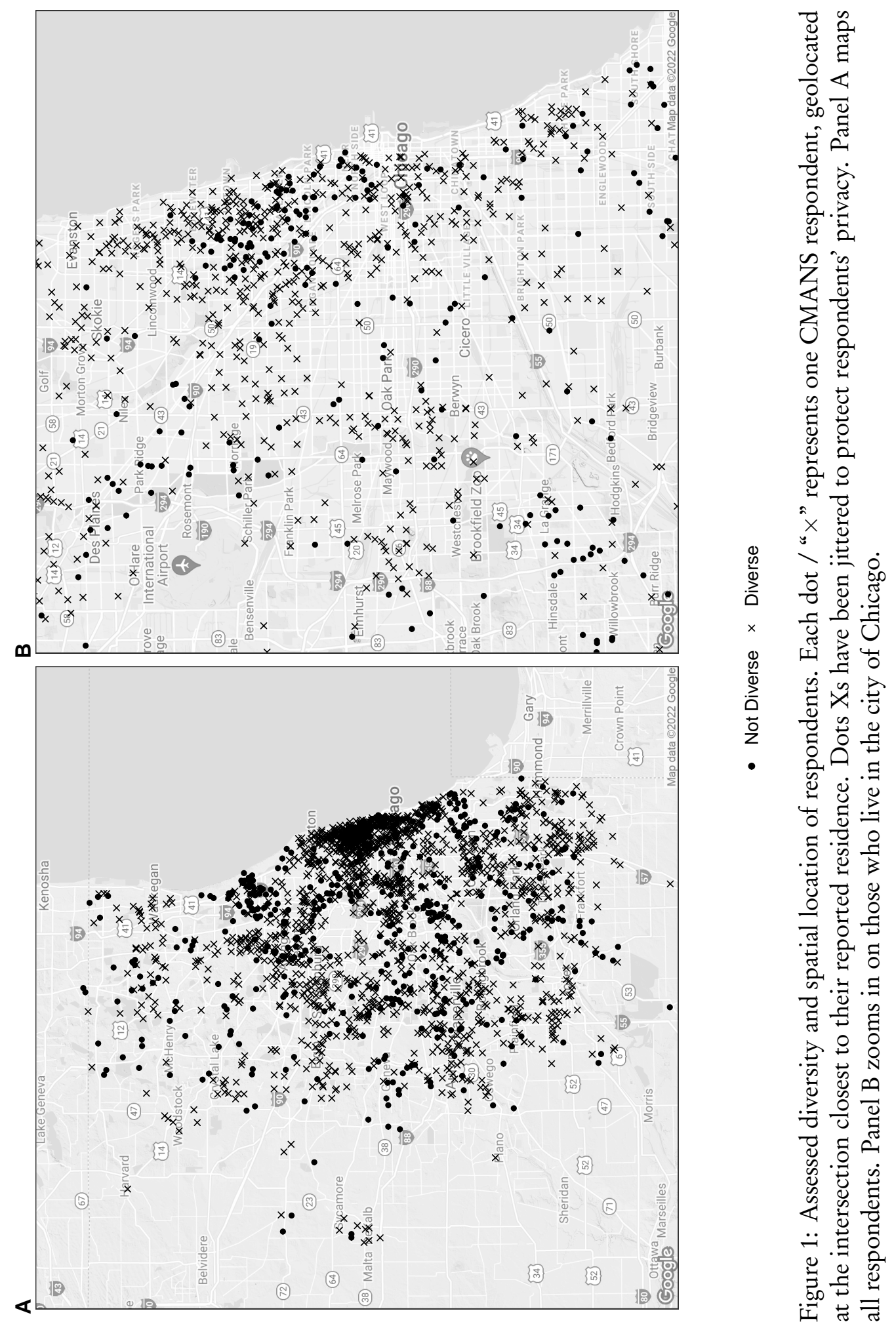



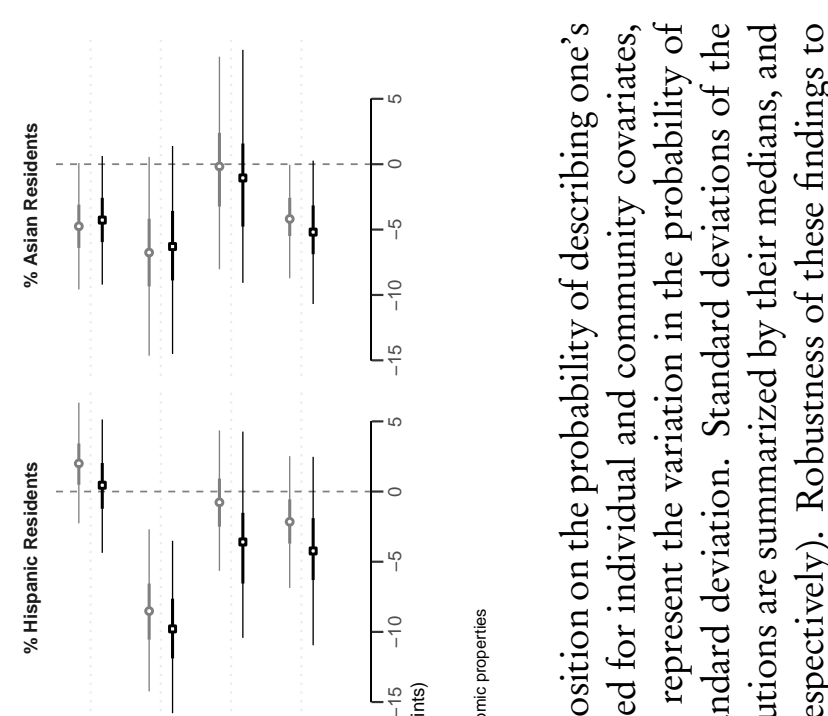

:
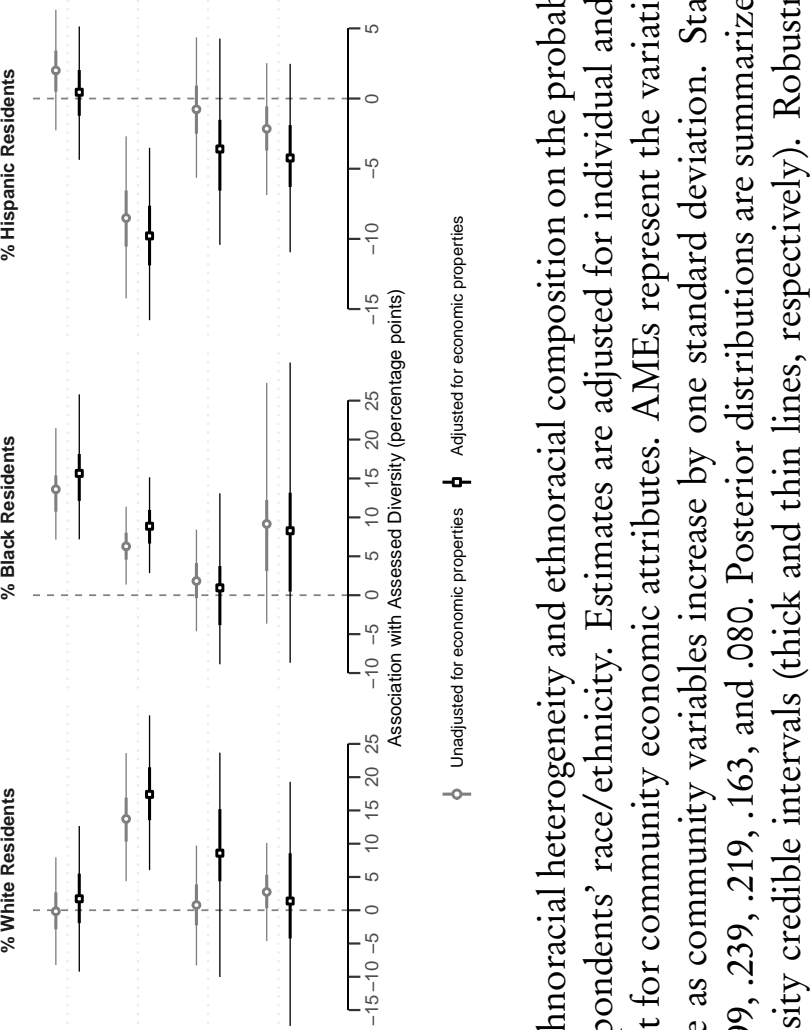

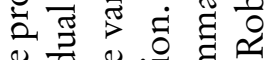

운

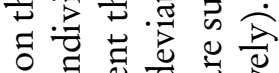

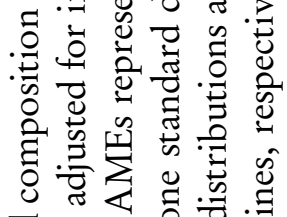

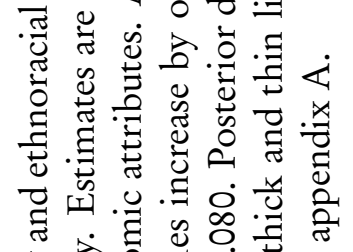

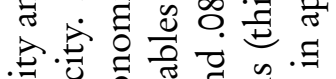

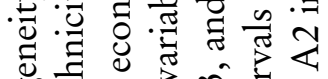

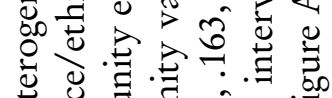

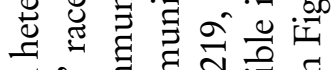

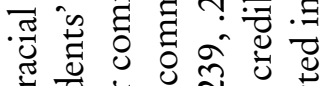

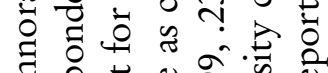

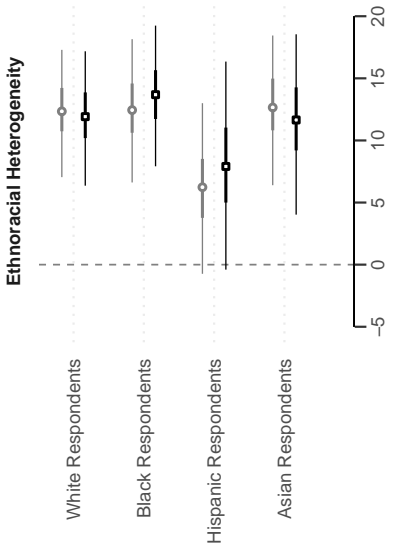

क्षे क्षे

पे

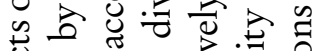

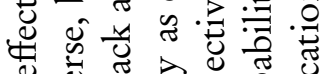

주의

政

๘

응

जु

워워

年

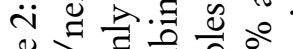

흘

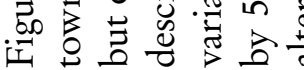


with an increase in assessed diversity of 16 percentage points, whereas a one-SD increase in the share of Asian residents (+.080) is associated with a decrease in assessed diversity of 4.9 points. Among White respondents, assessed diversity is not significantly associated with the shares of White or Hispanic residents. Chicago's historically White-Black racial landscape may account for the association White residents make between Black neighbors and diversity. Alternatively, or in addition, White residents may have an easier time racially classifying neighbors who identify as Black than those who identify as Hispanic or Asian (Abascal 2020).

For Black respondents, assessed diversity is significantly, positively associated with the share of White and Black residents and significantly, negatively associated with the share of Hispanic residents. As the shares of White or Black residents increase by one SD, assessed diversity increases by 15 and 8.6 percentage points. As the share of Hispanic residents increases by one SD, assessed diversity decreases by 8.8 points. Among Black respondents, assessed diversity is not significantly associated with the shares of Asian residents; however, the vast majority of the posterior probability mass is consistent with a negative association between assessed diversity and share of Asian residents. For Hispanic and Asian respondents, the associations are too imprecisely estimated to draw conclusions.

\section{Neighborhoods' Economic Attributes}

Next, we consider the association between assessed diversity and economic heterogeneity-represented by a Gini coefficient-and the representation of economically disadvantaged residents--represented by the poverty rate. Figure 3 reports estimates and credible intervals for the associations between assessed diversity and these indicators.

For White respondents, income inequality is negatively associated with assessed diversity, which is counterintuitive because inequality is a form of heterogeneity. As the Gini coefficient increases by one SD (+.049), the probability that a White respondent will describe their neighborhood as diverse decreases by 4.9 points, accounting for community ethnoracial attributes. For Black, Hispanic, and Asian respondents, the associations between assessed diversity and income inequality are also negative, but they are imprecisely estimated and do not reach significance.

Additionally, among White respondents, a one-SD increase in the poverty rate $(+.074)$ is associated with an 11-point increase in assessed diversity, consistent with the prediction that diversity is associated with the representation of disad- 


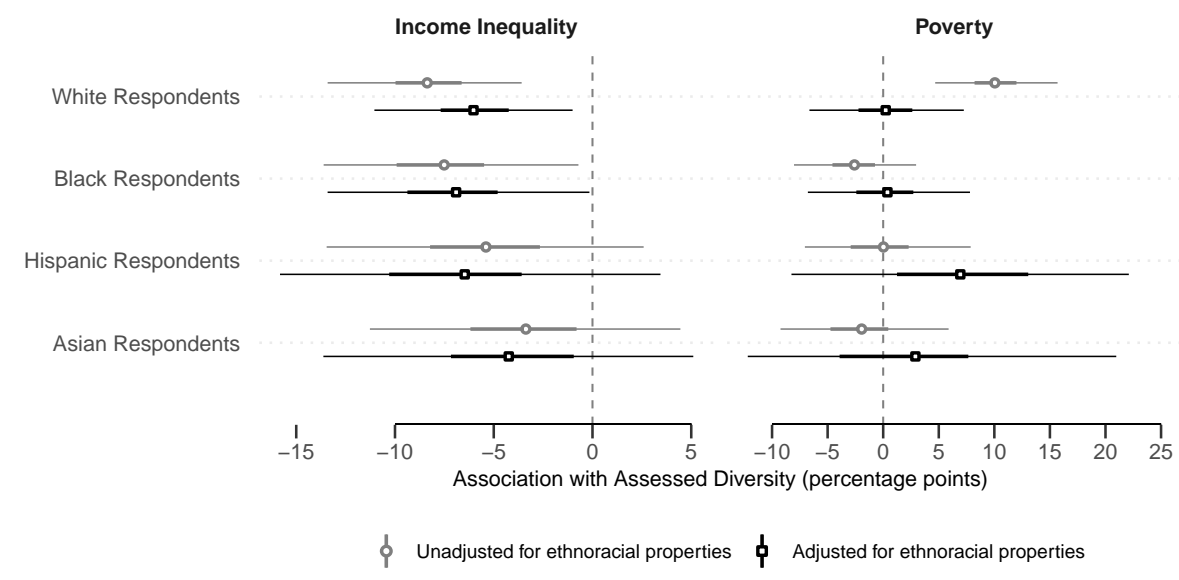

Figure 3: Average marginal effects of income inequality and poverty on the probability of describing one's town/neighborhood as diverse, by respondents' race/ethnicity. Estimates are adjusted for individual and neighborhood covariates, but only the estimates in black account for neighborhood ethnoracial attributes. AMEs represent the variation in the probability of describing a community as diverse as neighborhood variables increase by one standard deviation. Standard deviations of the variables of interest are respectively .049 and .074 . Posterior distributions are summarized by their medians, and by $50 \%$ and 95\% high probability density credible intervals (thick and thin lines, respectively). Robustness of these findings to alternative empirical specifications is reported in Figure A3 in appendix A. 
vantaged groups. This association, however, is confounded by community ethnoracial attributes, and once we adjust for these attributes, the AME drops to +1.3 points and its $95 \%$ credible interval substantially overlaps with zero. For Black, Hispanic, and Asian respondents, the associations between assessed diversity and community poverty rate are imprecisely estimated and do not reach significance.

In sum, whereas some respondents associate diversity with the representation of disadvantaged ethnoracial groups, there is no evidence that respondents associate diversity with the representation of disadvantaged economic groups. Meanwhile, economic heterogeneity in the form of income inequality unexpectedly predicts lower assessed diversity for White respondents.

\section{Relative Importance of Ethnoracial and Economic Attributes}

Which of these-ethnoracial attributes or economic attributes-better predicts the decision to describe a community as diverse? At first blush, it seems that community ethnoracial attributes-i.e., ethnoracial heterogeneity and ethnoracial group shares-better predict assessed diversity than community economic attributesi.e., income inequality and poverty rate. For non-White respondents, for example, assessed diversity is not significantly associated with any community economic attributes, but it is associated with some ethnoracial attributes. However, the picture is less clear for White respondents, for whom income inequality significantly predicts assessed diversity. To adjudicate, we calculate measures of explained variance based on Gelman et al.'s (2019) $R^{2}$ s for the Bayesian regression models. ${ }^{19}$ The analyses reveal that ethnoracial attributes explain $18.4 \%$ of the variance, whereas economic attributes explain just $2.6 \%$-a pattern that is replicated for Blacks, Hispanics, and Asians. In sum, and consistent with our initial impression, assessed diversity is more closely linked with community ethnoracial attributes than economic ones.

\footnotetext{
${ }^{19}$ We define the variance explained by a dimension as the difference between the $R^{2}$ of the model under complete data to the $R^{2}$ of the same model when the focal variable is fixed, so there is no variation in the sample. Specifically, we calculate Gelman et al.'s (2019) $R^{2}$ s using the posterior draws from our fully adjusted model and, for the second $R^{2}$, we set the focal variables to their means (or, when they are dependent by definition, to the sample value that minimizes the Euclidian distance to the means of these variables independently calculated).
} 
Why Are Whites Less Likely to Describe Economically Unequal Communities as Diverse?

White respondents are more likely to describe a town or neighborhood as diverse the less economically unequal-i.e., more economically homogeneous-it is. Can this association be accounted for by other differences between relatively unequal neighborhoods and relatively equal ones? Respondents' open-ended explanations for their characterizations of their neighborhoods yield several alternative hypotheses, each of which we examine quantitatively.

Ethnoracial Economic Integration.-A handful of open responses suggest that people are less likely to think of a town or neighborhood as diverse if ethnoracial groups are economically unequal. Describing her neighborhood, for example, one respondent wrote that it was "Predominantly white, Jewish background. When there are others of color, often performing lower level or labor intensive jobs." If economic inequality generally is associated with economic inequality across ethnoracial groups specifically, this may account for the fact that Whites are less likely to describe economically unequal communities as diverse.

To explore this, we include in our models an indicator of between-ethnoracial group inequality. This indicator corresponds to the variance between ethnoracial groups' per capita incomes in a community, weighted by the share in each group in that community. Results are reported in panel A, Figure 4. We find no evidence of an association between assessed diversity and between-ethnoracial group inequality for White respondents, conditional on our covariates. Income inequality-which becomes, in this model, a proxy for within-group inequalityremains negatively associated with assessed diversity for White respondents.

Residential and Network Segregation.-Alternatively, it may be that, as economic inequality goes up, neighborhood residents get sorted spatially and in their social networks along economic and ethnoracial lines, and they perceive the composition of their communities differently as a result. In their open responses, some respondents mentioned the spatial integration (or segregation) of different groups in their neighborhood. Some of these respondents referred to integration or segregation explicitly, like the respondent who wrote, "Integrated living arrangements, all races live by each other." Others alluded to it by describing spatial arrangements at a geographic level smaller than the town or neighborhood, like the respondent who wrote, "The black people who do live here are concentrated in one part of the town." Overall, very few respondents (1.70\%) mentioned spatial 
A

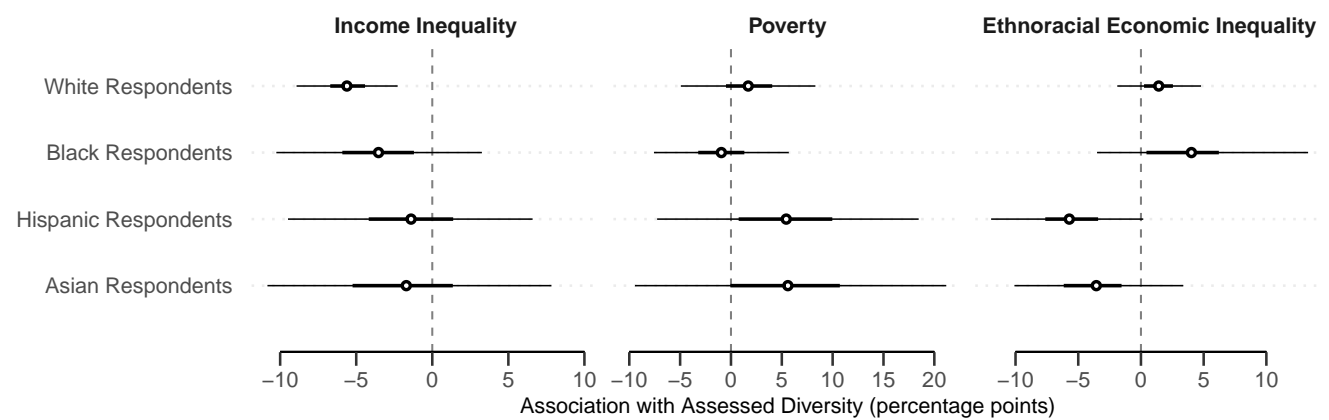

B

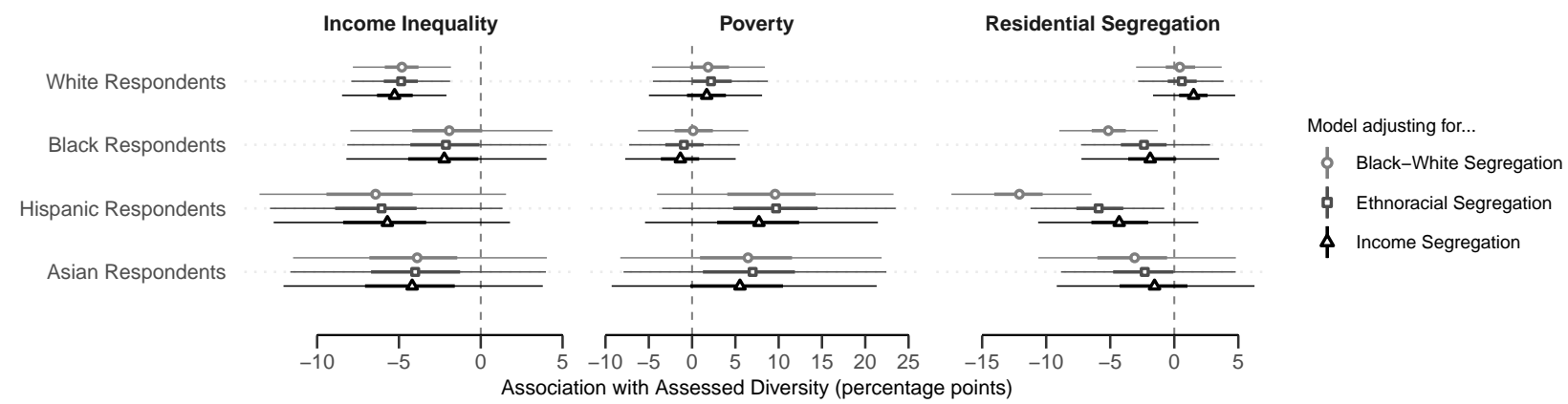

C

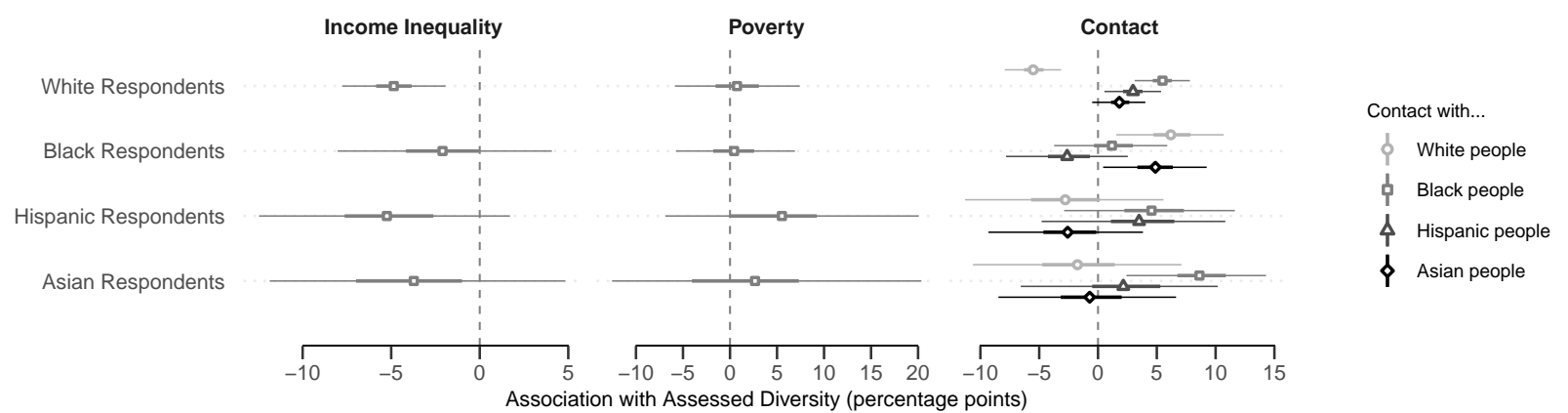

D

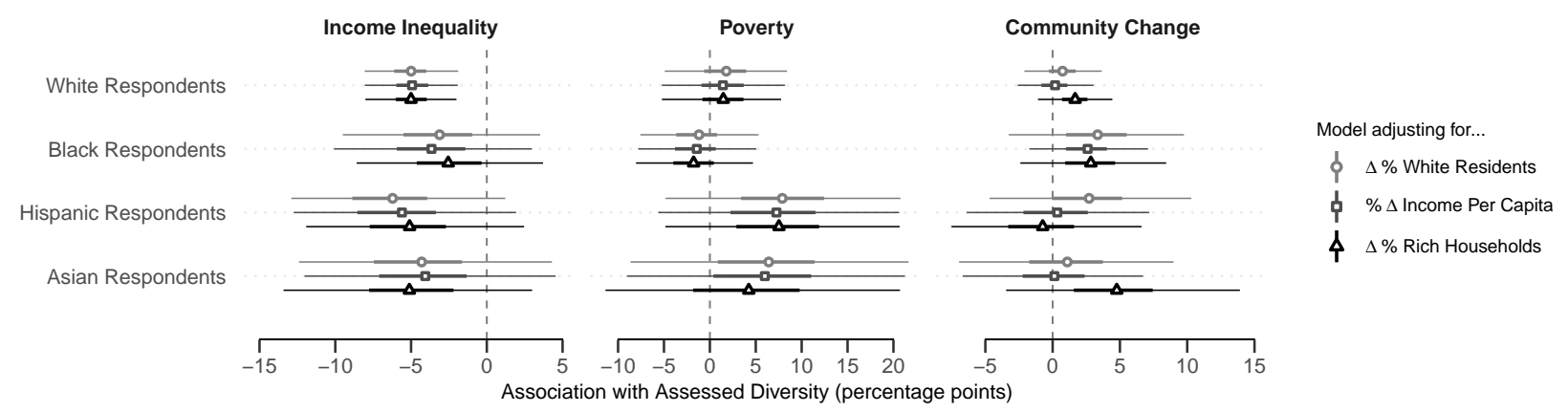

Figure 4: Average marginal effects of income inequality, poverty, and between-ethnoracial group inequality (panel A), measures of residential segregation (panel B) and network integration (panel C), and measures of community change (panel D) on the probability of describing one's town/neighborhood as diverse, by respondents' race/ethnicity. AMEs represent the variation in the probability of describing a neighborhood as diverse as community variables increase by one standard deviation (see Table A1, in appendix A, for descriptive statistics of these variables). Posterior distributions are summarized by their medians, and by $50 \%$ and $95 \%$ high probability density credible intervals (thick and thin lines, respectively). 
integration or its absence. However, these responses were patterned by assessed diversity. Of those respondents who described their neighborhood as "diverse," $1.83 \%$ alluded to the spatial integration of residents, compared to just $0.62 \%$ of those who described their neighborhood as "not diverse" $(p<0.05)$.

One pathway through which ethnoracial segregation could affect assessed diversity is by limiting contact between ethnoracial groups. Given that Whites are more likely to describe their community as diverse the greater the share of Black residents, if segregation means a White resident is less likely to come in contact with/be aware of her Black neighbors, they should also be less likely to describe their community as diverse. As a result, segregation, if associated with economic inequality, may account for the that fact economically unequal neighborhoods are also less likely to be described as diverse.

We capture ethnoracial residential segregation using a classic dissimilarity index between White and Black residents, where segregation is considered within communities, between block groups. We also calculated an alternative, entropybased measure of segregation that accounts for spatial segregation between all ethnoracial groups, not just Whites and Blacks. Finally, we consider a measure of income segregation, which we compute as the ratio of between-block group income inequality to community income inequality, both represented by Gini coefficients (for a discussion of the limits of this measure, see Reardon and Bischoff 2011).

Estimates of the parameters of interest from models that adjust for residential segregation are reported in panel B of Figure 4. For White respondents, neither ethnoracial residential segregation nor income residential segregation is associated with lower assessed diversity. Moreover, we find no evidence that segregation accounts for the association between economic inequality and assessed diversity. Indeed, conditional on residential segregation, the association between income inequality and assessed diversity remains unchanged.

We also test this hypothesis using a subjective measure of contact with different ethnoracial groups, using an item from CMANS that asks how often respondents have unplanned contact with Whites, Blacks, Hispanics, or Asians. Panel C of Figure 4 shows the estimates from a model that includes these variables; while they do predict assessed diversity, they do not account for the association between income inequality and perceived diversity. Taken together, the findings do not support the hypothesis that spatial and network segregation are responsible for the relationship between inequality and assessed diversity. 
Community Change and Gentrification.-In their open responses, a small number of respondents described changes in the composition of their town or neighborhood. About one-quarter of these referred explicitly to gentrification, to the inmigration of White or affluent residents, or to the out-migration of non-White or poor residents. As one respondent who described her neighborhood as "not diverse" put it, "It is a highly gentrified neighborhood with little racial/ethnic diversity." In her estimation, gentrification and diversity are antithetical. The progressive activists in Berrey's (2005) ethnography of Rogers Park, Chicago similarly framed gentrification as a threat to diversity. If gentrifying communities, which are likely more economically unequal communities, are less likely to be described as diverse, then gentrification may account for the fact economically unequal communities are also less likely to be described as diverse.

For this analysis, we operationalize community change in three ways: first, as the change in the share of White residents in the community; second, as the growth rate of per capita income in the community; and third, as the change in the share of affluent households in the community. ${ }^{20}$ Changes are calculated between the ACS 5-year estimates from 2009 to 2013 and from 2014 to 2018.

Results from models that include these indicators are reported in panel D, Figure 1. None of the measures of community change that we tested are associated with assessed diversity. Accordingly, accounting for neighborhood change does not substantially affect the association between income inequality and assessed diversity. These findings hold if we consider a slightly longer period, from the ACS 5-year estimates from years 2007 to 2010 (Figure A4, in the supplemental information).

In sum, between-ethnoracial group economic inequality, racial and economic residential segregation, and community change do not explain the negative association between economic inequality and assessed diversity for White respondents. It is possible that unobserved community traits that are correlated with income inequality explain the association between assessed diversity and economic inequality. As just one example: If shops, restaurants, and other visible local institutions are more ethnoracially mixed in more economically equal communities, this could account for the counterintuitive pattern observed. However, we would be remiss not to acknowledge a more straightforward possibility: that economic inequality detracts from perceived diversity in the minds of White respondents.

${ }^{20} \mathrm{~A}$ household is classified as affluent if household income equals or exceeds $\$ 125,000$ (in 2018 US\$), which roughly corresponds to twice the median household income in 2018. 
Recall that diversity is endowed with a positive normative connotation, even if that connotation does not automatically translate into support for pro-diversity policies (Warikoo 2016). Diversity might therefore be opposed to an undesirable community trait, like economic inequality. Specifically, if the notion of diversity goes beyond the mere co-presence of heterogeneous people to encompass ideals of inclusion, integration, and power and resource equity, then economic inequality-which involves hierarchical differences-may be at odds with diversity.

\section{DISCUSSION}

Our quantitative and qualitative analyses reveal that diversity is more strongly associated with a town or neighborhood's ethnoracial attributes than its economic ones. Quantitative analyses further indicate that ethnoracial heterogeneity predicts the decision to describe a community as diverse among White, Black, and Asian respondents. Ethnoracial group shares also predict the decision to describe a neighborhood as diverse, but these associations vary by the race/ethnicity of both the respondent and the target group. Most notably, both Whites and Blacks associate the share of Blacks with greater diversity.

Although there is some evidence that respondents associate diversity with the representation of disadvantaged ethnoracial groups, there is no evidence that they associate it with the representation of disadvantaged economic groups, i.e., poor people. In addition, only Whites associate economic inequality with diversity; counterintuitively, they are less likely to describe economically unequal neighborhoods as diverse. This association is not accounted for by between-group inequality, segregation, or neighborhood change. Although inequality is a form of heterogeneity, its negative connotation may be at odds with diversity's positive normative inflection. Future research should further probe whether diversity is indeed understood as a benevolent force that is at odds with inequality and other objectionable qualities.

To what extent are the effects of neighborhood ethnoracial and economic attributes mediated through the composition of respondents' social networks? As we are reminded by recent ethnographic research (based, fittingly, on Rogers Park, the "most diverse" neighborhood in Chicago), heterogeneity in terms of census statistics does not necessarily translate into heterogeneous interactions on the ground (Garcia 2017). Our analyses of network segregation yield prima facie evidence, especially among White respondents, that respondents who report more 
unplanned neighborhood contacts with people of other ethnoracial backgrounds are more likely to describe their neighborhoods as diverse. However, the available measures of network segregation are fairly crude, and future research should further explore the role of social networks in perceptions of neighborhood diversity.

Our findings are based on the Chicago metro area, a propitious research site where neighborhood boundaries are widely agreed-upon and where communities vary widely in terms of ethnoracial and economic composition. Does Chicago's unique multiethnic character, in particular its historically White-Black racial landscape, account for our findings, especially the fact that White and Black residents associate diversity with Black representation? We raise two caveats: First, we should not overstate Chicago's White-Black binary; for example, Chicago's sizable Mexican-origin population began immigrating in the 1910s (Innis-Jiménez 2013). Second, experimental research with a nationally representative sample finds that Americans', and especially Whites', assessments of diversity hinge on the presence of Blacks (Abascal et al. 2021b). And, despite our focus on Chicago, the preeminence of race/ethnicity we observed also emerged in Bell and Hartmann's (2007) interview study of Atlanta, Boston, Los Angeles, and the Twin Cities (also see Hoekstra and Gerteis 2019) and Rajasekar et al.'s (2021) quantitative study of US counties. Still, future research would do well to examine understandings of diversity in other cities with different ethnoracial and economic compositions and histories. Such research might also calculate heterogeneity based on more finegrained ethnoracial distinctions-e.g., Mexican, Puerto Rican, Dominican, etc.

Our empirical strategy assumes that the way we define towns and neighborhoods matches respondents' definitions. We are not able to check this assumption empirically, but we know that the characteristics of neighborhoods and towns, as we define them, predict residents' assessment of diversity. In addition, the demographic and economic composition of these neighborhoods and towns should be correlated with those of the smaller units they contain and which respondents might be envisioning. Importantly, our findings are virtually identical when we look at census tracts, rather than neighborhoods and towns (Appendix A, Figures A2 and A3).

Although we stratified our sample by respondents' race/ethnicity, we did not explore how other respondent traits and attitudes may modulate their evaluations of diversity. Two factors, in particular, merit further investigation: respondents' political views and their endorsement of "diversity" broadly. Impor- 
tantly, our results are robust controlling for respondents' self-reported partisanship and views on community diversity (Appendix A, Figures A2 and A3). Future work, however, should explore whether these and similar measures-including measures of colorblind racism, symbolic racism, racial group competition, and racial stereotypes-moderate the statistical effects of ethnoracial heterogeneity (and other factors) on assessed diversity. Recent work by Abascal et al. (2021b), for example, suggests that the effect of ethnoracial group shares on assessed diversity is moderated by Whites' support for immigration and affirmative action. Notably, however, Rajasekar et al. (2021) find that individual racial attitudes play only a minor role in predicting assessed diversity, and they do not alter the relationship between assessed diversity and community composition.

Our study focused on assessments of residential communities, as opposed to educational, professional, or other communities. Neighborhoods and towns may be subject to narrower definitions of diversity than schools or workplaces, where other traits-particularly gender-should also be salient. Recall that qualitative research in educational and corporate settings finds diversity is not infrequently construed in idiosyncratic and even outlandish ways, e.g., being home-schooled or bringing a dog to work (Kirkland and Hansen 2011; Embrick 2011). By implication, the meanings of diversity may be even broader-and more ambiguous-in non-residential contexts. We discuss the implications of diversity ambiguity next.

\section{CONCLUSION}

Our findings corroborate, and sometimes qualify, concerns about diversity discourse, while raising new ones. First, consider diversity's association with multiple types of difference. Scholars have long criticized "diversity" for its ability to subsume too many traits, in essence treating them as analogous (Berrey 2005, 2015; Lentin and Titley 2008:e.g.,). Indeed, we find that some respondents link diversity not to race/ethnicity or socioeconomic status, but to age, religion, political affiliation, gender and sexual identity, family configurations, "shapes," "walks of life," and other attributes. On the other hand, our findings indicate that diversity still retains its primary association with race/ethnicity (Bell and Hartmann 2007; Rajasekar et al. 2021). Both our quantitative and qualitative analyses make clear that ethnoracial attributes best predict the decision to describe a neighborhood as diverse. And, in the open-response data, explanations that invoke ethnoracial/national differences are dominant: they are proffered by nearly nine in ten respondents. 
Diversity's simultaneous association with two dimensions of the same difference-ethnoracial heterogeneity and ethnoracial group shares-raises another set of issues. These dimensions are not only distinct, they are occasionally orthogonal, as in homogeneously Black neighborhoods. Prior research on the meanings of diversity had not considered this particular source of ambiguity, but it carries direct implications for social science research and associated policies. Elision between ethnoracial heterogeneity and representation suffuses the massive literature on the undesirable effects of community diversity for social capital and public goods provision. Some of these studies directly measure "diversity" using immigrant or non-White shares (Dinesen et al. 2020; for a discussion see Abascal et al. 2021a). Others use heterogeneity indexes that are collinear with immigrant or non-White shares in Western countries where homogeneous communities are, by and large, homogeneously native, White communities (Kustov and Pardelli 2018). Their alarmist conclusions about the undesirable effects of diversity are interpreted, in turn, by a lay audience that strongly, perhaps principally, conceives of diversity as heterogeneity, i.e., mixture. The outcome reads like a cautionary tale: Findings which probably indicate that native majorities object to the presence of immigrants and minorities are used to oppose ethnoracial mixture and the policies, like affirmative action and open immigration, that promote it (Thernstrom et al. 2012; Richwine 2009). Opposition is abetted by a research literature that insists on making claims about "diversity," claims that allow (and possibly lead) readers to see mixture, rather than prejudice or disadvantage, as the problem.

Diversity's association with multiple differences as well as with multiple dimensions of the same difference insinuate a troubling possibility: People who wish to describe their communities as diverse can almost always do so, even if those communities are neither ethnoracially heterogeneous nor substantially non-White. One trick would be to (re)define diversity in terms of one of the infinitely many attributes along which people can vary. Examples from school and workplace settings provide suggestive evidence of this tendency. In these settings, even people who oppose "diversity policies" sometimes frame their arguments in terms of "diversity." For example, conservative groups on a college campus opposed affirmative action by claiming that it would undermine the "diversity of ideas" (Berrey 2015:109). ${ }^{21}$ And in an experimental setting, anti-egalitarian par-

\footnotetext{
${ }^{21}$ For examples among upper-level corporate managers, see Embrick (2011:548-549).
} 
ticipants reframed an ethnoracially homogeneous organization as occupationally diverse in order to justify their continued opposition to affirmative action (Unzueta and Binning 2010).

Is diversity more likely to be associated with non-ethnoracial attributes in neighborhoods that cannot be plausibly characterized as ethnoracially diverse, in terms of either heterogeneity or representation? Is this tendency stronger for those residents-like liberal Whites-who are probably more motivated to describe their neighborhoods as diverse? These questions present promising areas for further research.

\section{REFERENCES}

Abascal, Maria. 2020. "Contraction as a response to group threat: Demographic decline and Whites' classification of people who are ambiguously White." American Sociological Review 85(2):298-322.

Abascal, Maria and Delia Baldassarri. 2015. "Love Thy Neighbor? Ethnoracial Diversity and Trust Reexamined." American Journal of Sociology 121(3):722782.

Abascal, Maria, Flavien Ganter, and Delia Baldassarri. 2021a. "Greater Diversity or Fewer Whites? Disentangling Heterogeneity and Minority Share at Macro and Micro Levels." SocArXiv. doi: 10.31235/osf.io/ve4aw.

Abascal, Maria, Janet Xu, and Delia Baldassarri. 2021b. "Americans Use Both Heterogeneity and Minority Representation to Evaluate Diversity." Science Advances 7(11).

Alba, Richard D., Ruben G. Rumbaut, and Karen Marotz. 2005. "A Distorted Nation: Perceptions of Racial/Ethnic Group Sizes and Attitudes Toward Immigrants and Other Minorities.” Social Forces 84(2):901-919.

Armentrout, Mitchell. 2017. "Census: Hispanics Surpass Blacks as Chicago's 2ndLargest Racial Group.” Chicago Sun Times September 14.

Bauman, Christopher W., Sophie Trawalter, and Miguel M. Unzueta. 2014. "Diverse According to Whom? Racial Group Membership and Concerns About Discrimination Shape Diversity Judgments." Personality and Social Psychology Bulletin 40(10):1354-1372.

Bell, Joyce M. and Douglas Hartmann. 2007. "Diversity in Everyday Discourse: The Cultural Ambiguities and Consequences of 'Happy Talk'." American Sociological Review 72:895-914.

Berrey, Ellen. 2005. "Divided over Diversity: Political Discourse in a Chicago Neighborhood.” City E Community 4(2):143-170. 
Berrey, Ellen. 2015. The Enigma of Diversity: The Language of Race and the Limits of Racial Justice. Chicago and London: University of Chicago Press.

Blau, Peter M. 1977. “A Macrosociological Theory of Social Structure.” American Journal of Sociology 83(1):26-54.

Bonilla-Silva, Eduardo. [2003] 2018. Racism without racists: Color-blind racism and the persistence of racial inequality. Lanham, MD: Rowman \& Littlefield.

Burke, Meghan A. 2012. Racial Ambivalence in Diverse Communities: Whiteness and the Power of Color-blind Ideologies. Plymouth, UK: Lexington Books.

City of Chicago. 2006. "Chicago Neighborhoods." Map, https: //www.chicago.gov/content/dam/city/depts/doit/general/GIS/Chicago_ Maps/Citywide_Maps/City_Neighborhoods_1978_11x17.pdf.

Collins, Sharon M. 2011. "Diversity in the Post Affirmative Action Labor Market: A Proxy for Racial Progress?” Critical Sociology 37(5):521-540.

Darrah-Okike, Jennifer, Hope Harvey, and Kelley Fong. 2020. “Because the World Consists of Everybody': Understanding Parents' Preferences for Neighborhood Diversity." City \& Community 19(2):374-397.

Dinesen, Peter T., Merlin Schaeffer, and Kim Mannemar Sønderskov. 2020. "Ethnic Diversity and Social Trust. A Narrative and Meta-Analytical Review." Annual Review of Political Science 23.

Doane, Ashley "Woody". 2017. "Beyond Color-blindness: (Re)Theorizing Racial Ideology.” Sociological Perspectives 60(5):975-991.

Edelman, Lauren B., Sally Riggs Fuller, and Iona Mara-Drita. 2001. "Diversity Rhetoric and the Managerialization of Law." American Journal of Sociology 106(6).

Embrick, David G. 2011. "The Diversity Ideology in the Business World: A New Opression for a New Age.” Critical Sociology 37(5):541-556.

Garcia, Denia. 2017. Integration Beyond Numbers: Getting Along and Working Together in a Multiethnic Neighborbood. Ph.D. thesis, Princeton University, Princeton.

Gelman, Andrew, Ben Goodrich, Jonah Gabry, and Aki Vehtari. 2019. "RSquared for Bayesian Regression Models." The American Statistician 73(3):307309.

Hirschman, Daniel, Ellen Berrey, and Fiona Rose-Greenland. 2016. "Dequantifying Diversity: Affirmative Action and Admissions at the University of Michigan." Theory and Society 45(3):265-301.

Hoekstra, Erin and Joseph Gerteis. 2019. "The Civic Side of Diversity: Ambivalence and Belonging at the Neighborhood Level." City E Community 18(1):195212.

Holli, Melvin G. and Peter d'A Jones (eds.). 1995. Ethnic Chicago: A Multicultural Portrait. Grand Rapids: Wm. B. Eerdmans Publishing Co. 
Innis-Jiménez, Michael. 2013. Steel Barrio: The Great Mexican Migration to South Chicago, 1915-1940. New York: New York University Press.

Kelly, Erin and Frank Dobbin. 1998. "How Affirmative Action Became Diversity Management: Employer Responses to Antidiscrimination Law, 1961 to 1996." American Behavioral Scientist 41(7):960-984.

Kirkland, Anna and Ben B. Hansen. 2011. "'How do I Bring Diversity?' Race and Class in the College Admissions Essay.” Law E Society Review 45(1):103-138.

Krysan, Maria. 1998. "Privacy and the Expression of White Racial Attitudes: A Comparison Across Three Contexts." Public Opinion Quarterly 62(4):506-544. Krysan, Maria, Courtney Carter, and Marieke van Londen. 2016. "The Diversity of Integration in a Multiethnic Metropolis." Du Bois Review 14(1):35-71.

Kustov, Alexander and Giuliana Pardelli. 2018. "Ethnoracial Homogeneity and Public Outcomes: The (Non)effects of Diversity." American Political Science Review .

Lentin, Alana and Gavan Titley. 2008. "More Benetton Than Barricades? The Politics of Diversity in Europe." In The Politics of Diversity in Europe, edited by Gavan Titley and Alana Lentin, pp. 9-28. Strasbourg: Council of Europe Publishing.

Logan, John R. and Brian J. Stults. 2011. "The Persistence of Segregation in the Metropolis: New Findings from the 2010 Census." Census Brief prepared for Project US2010.

Logan, John R. and Charles Zhang. 2010. "Global Neighborhoods: New Pathways to Diversity and Separation.” American Journal of Sociology 115(4):10691109.

Mayorga-Gallo, Sarah. 2014. Behind the White Picket Fence: Power and Privilege in a Multiethnic Neighborhood. Chapel Hill: The University of North Carolina Press.

Mayorga-Gallo, Sarah. 2019. "The White-Centering Logic of Diversity Ideology.” American Behavioral Scientist 63(13):1789-1809.

Moore, Wendy Leo and Joyce M. Bell. 2011. "Maneuvers of Whiteness: 'Diversity' as a Mechanism of Retrenchment in the Affirmative Action Discourse." Critical Sociology 37(5):597-613.

Okuwobi, Oneya, Deborwah Faulk, and Vincent J. Roscingo. 2021. "Diversity Displays and Organizational Messaging: The Case of Historically Black Colleges and Universities." Sociology of Race and Ethnicity 7(3):384-400.

Posner, Daniel N. 2004. "Measuring Ethnic Fractionalization in Africa." American Journal of Political Science 48(4):849-863.

Putnam, Robert D. 2007. "E Pluribus Unum: Diversity and Community in the Twenty-first Century." Scandinavian Political Studies 30(2):137-174. 
Rajasekar, Neeraj, Evan Stewart, and Joseph Gerteis. 2021. "Assessing Local 'Diversity': A Nationally Representative Analysis.” Social Currents 9(2):139-158.

Reardon, Sean F. and Kendra Bischoff. 2011. "Income Inequality and Income Segregation.” American Journal of Sociology 116(4):1092-1153.

Richwine, Jason. 2009. "A Smart Solution to the Diversity Dilemma."

Sampson, Robert J. 2012. Great American City: Chicago and the Enduring Neighborhood Effect. Chicago and London: University of Chicago Press.

Stan Development Team. 2018. "Stan Modeling Language Users Guide and Reference Manual." http://mc-stan.org.

Thernstrom, Abigal, Stephan Thernstrom, Althea K. Nagai, and Russell Nieli. 2012. "Brief in Support of Petitioners as Amici Curiae." Fisher vs. University of Texas, U.S. 11-345.

Underhill, Megan R. 2019. “'Diversity Is Important to Me': White Parents and Exposure-to-Diversity Parenting Practices." Sociology of Race and Ethnicity 5(4):486-499.

Unzueta, Miguel M. and Kevin R. Binning. 2010. "Which Racial Groups are Associated with Diversity." Cultural Diversity and Ethnic Minority Psychology 16(3):443-446.

Unzueta, Miguel M., Eric D. Knowles, and Geoffrey C. Ho. 2012. "Diversity is What You Want it to be: How Social-Dominance Motives Affect Construals of Diversity." Psychological Science 23(3):303-309.

van der Meer, Tom and Jochem Tolsma. 2014. "Ethnic Diversity and Its Effects on Social Cohesion." Annual Review of Sociology 40:459-478.

Vertovec, Steven. 2012. “'Diversity' and the Social Imaginary." European Journal of Sociology 53(3):287-312.

Warikoo, Natasha K. 2016. The Diversity Bargain, And Other Dilemmas of Race, Admissions, and Meritocracy at Elite Universities. Chicago: The University of Chicago Press.

Wong, Cara J. 2007. "'Little" and "Big" Pictures in Our Heads: Race, Local Context, and Innumeracy about Racial Groups in the United States." The Public Opinion Quarterly 71(3):392-412.

Zhang, Wenquan and John R. Logan. 2016. "Global Neighborhoods: Beyond the Multiethnic Metropolis.” Demography 53(6):1933-1953. 